\begin{tabular}{|c|c|c|}
\hline $\begin{array}{l}\text { PKS } \\
\text { PUBLC } \\
\text { KNOWLDGE } \\
\text { PROJECT }\end{array}$ & $\begin{array}{c}\text { REVISTA DE GEOGRAFIA } \\
\text { (RECIFE) } \\
\text { http://www.revista.ufpe.br/revistageografia }\end{array}$ & 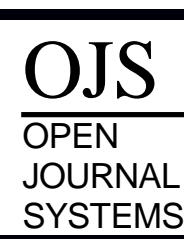 \\
\hline
\end{tabular}

\title{
ELEMENTOS NATURAIS QUE FUNDAMENTAM A CONSERVAÇÃO DAS SERRAS SEMIÁRIDAS DO CENTRO- OESTE CEARENSE
}

\author{
Raul Carneiro Gomes ${ }^{1}$, Laura Gomes Girão Paiva², Vládia Pinto Vidal de Oliveira ${ }^{3}$
}

\begin{abstract}
${ }^{1}$ Doutorando do Programa de Pós-Graduação em Geografia da Universidade Federal do Ceará. Email: raulcarneiro89@hotmail.com

${ }^{2}$ Mestre em Geologia Ambiental pela Universidade Federal do Ceará. Email: laura_gomesgirao@hotmail.com

${ }^{3}$ Professora do departamento de Geografia da Universidade Federal do Ceará. Email: vladia.ufc@gmail.com
\end{abstract}

Artigo recebido em 21/01/2017 e aceito em 20/09/2017

\begin{abstract}
RESUMO
Ocorrem, no Centro-Oeste do Ceará-Brasil, maciços estruturais denominados de serras secas que, em meio à degradação do pediplano adjacente, transformaram-se em espaços estratégicos para ao desenvolvimento social e para a conservação dos recursos hídricos, da fauna e da flora. Este estudo objetivou indicar os elementos naturais que fundamentam a conservação das serras secas, pretendendo subsidiar a sua proteção e o seu ordenamento territorial. Assim, executou-se levantamentos bibliográficos, geocartográficos e o reconhecimento dos componentes geoambientais em campo, obtendo dados sobre a flora, a fauna, os relevos, os recursos hídricos e seus processos interativos. Constatou-se que as serras examinadas têm vegetação de caatinga na qual se destaca a aroeira (Myracrodruon urundeuva) e são habitats de espécies faunísticas como: cassaco (Didelphis albiventris), tamanduá-mirim (Tamandua tetradactyla), onça-parda (Puma concolor), tatu (Tolypeutes tricinctus), peba (Euphractus sexcinctus) e veado catingueiro (Mazama gouazoupira) que são predados ou mortos. Os relevos oferecem limitações para a agropecuária devido à ocorrência de vertentes declivosas, às estruturas de fraturas e falhas que propiciam eventos de deslizamento e queda de blocos. Ademais, o desmatamento da caatinga arbóreaarbustiva potencializa a instabilidade das vertentes pela erosão laminar e concentrada nos Cambissolos Háplicos e Neossolos Litólicos, proporcionando o assoreamento de nascentes, rios e reservatórios hídricos.
\end{abstract}

Palavras-chave: maciços cristalinos; degradação; semiárido.

\section{NATURAL ELEMENTS THAT JUSTIFY THE CONSERVATION OF THE SEMI-ARID MOUNTAINS OF THE CENTRAL WEST REGION OF THE STATE OF CEARA, BRAZIL}

\begin{abstract}
In the Center-West of Ceará, Brazil, there are massive formations known as semiarid mountains that, among the degradation of the adjacent pediplain, have become strategic spaces for social development and the conservation of water resources, fauna and flora. This study aimed at indicating the natural elements that justify the conservation of the semiarid mountains, to subsidize their protection and land use planning. For that, bibliographical, field geo-cartographic surveys and the recognition of geo-environmental components were carried out, obtaining data on flora, fauna, reliefs, water resources and their interactive processes. The semiarid mountains that were studied have caatinga vegetation - in which the aroeira (Myracrodruon urundeuva) stands out - and are habitats of animal species such as cassaco (Didelphis albiventris), tamanduá-mirim (Tamandua tetradactyla), onça-parda (Puma concolor), tatu (Tolypeutes tricinctus), peba (Euphractus sexcinctus) and veado catingueiro (Mazama gouazoupira), which are either preyed or killed. The reliefs offer limitations for agriculture and livestock due to the occurrence of sloping slopes, fracture and failure structures that provide sliding and
\end{abstract}


falling events. Furthermore, the deforestation of the caatinga's arboreal-shrub enhances the instability of the slopes by laminar and concentrated erosion on the Cambissolos and Neossolos Litólicos, providing sedimentation of springs, rivers and water resources.

Key-words: massive formations; degradation; semiarid.

\section{INTRODUÇÃO}

O estado do Ceará, Brasil, está compartimentado em diversas unidades geoambientais, que apresentam características socioambientais peculiares. Dentre esses geoambientes, destacam-se os Maciços Estruturais (ME), elevações com 400 a 1160 metros (m) de altitude, que caracterizam feições de soerguimento oriundas de reativações tectônicas, sucedidas por erosão diferencial, que despontam em relação ao pediplano circundante (MAIA; BEZERRA, 2014).

Por estarem em zonas de cizalhamentos, os ME resultam de intensos tectonismos plásticos e rupturais em granitóides, micaxistos, metagabros, gnaisses e anfibolitos esculpidos pela erosão diferencial (CAVALCANTE et al., 2003; MAIA; BEZERRA, 2014). Estas elevações habitualmente são dissecadas em colinas convexadas ou constituem-se de alinhamentos de cristas residuais e lombas alongadas que confinam vales fluviais em forma de V. Suas vertentes, frequentemente, exibem escarpas ou caos de blocos constituídos por granitos, quartzitos e paragnaisses do embasamento cristalino (SOUZA, 2007).

Geralmente, no Ceará, os ME podem ser diferenciados em secos/semiáridos e úmidos. Estas designações dependem de critérios como altitude, proximidade com o litoral e influências de massas de ar úmidas, que determinam aportes irregulares de umidade. Tal caracterização possibilita a existência de geoambientes com condições morfológicas, climáticas, pedológicas, botânicas e de uso-ocupação particulares (RODRIGUEZ; SILVA, 2002; SOUZA; OLIVEIRA, 2006).

Dentre os ME cearenses, Meruoca, Uruburetama, Baturité, Aratanha e Maranguape destacam-se por serem ME úmidos, dada às atuações dos climas tropicais quentes subúmido ou úmido (CEARÁ, 1997). Esses são provenientes das ações das massas de ar úmidas oceânicas (atlântica) e do efeito orográfico, decorrente de altitudes superiores a 600m.

Deste modo, os relevos citados apresentam pluviometrias médias superiores a $1200 \mathrm{~mm}$ anuais, rios perenes e podem conter relevos mamelonares em seus topos, conforme há no ME de Baturité (SOUZA; OLIVEIRA, 2006; BETARD; PEULVAST; CLAUDINOSALES, 2007). Além disso, a vegetação presente nos aludidos, frequentemente, é representada pela floresta subperenifólia tropical plúvio-nebular, enquanto que os seus solos 
são classificados como Argissolos Vermelhos/Amarelos e Latossolos Vermelhos/Amarelos (BRASIL, 1973; CEARÁ, 1997; 2006).

Já as Serras das Matas, Feijão, Azul, Boa Viagem, Conceição, Pipoca e Tecelão, apesar de possuirem cotas altimétricas superiores a 700m, são ME secos, uma vez que estão submetidos ao clima tropical quente semiárido (CEARÁ, 1997). Este ocorre em razão da continentalidade e da baixa incidência das massas de ar úmidas nestes relevos.

Nessa perspectiva, tais modelados apresentam condições geobotânicas distintas aos ME úmidos, pois suas precipitações médias anuais são em torno de 800mm (CEARÁ, 1997), irregulares no tempo e no espaço e, frequentemente, há ocorrências totais pluviométricos abaixo de 400mm nos anos estios.

Diante da baixa umidade destes geossistemas, os relevos são modelados, significativamente, pela regressão paralela e sua drenagem é êfemera e/ou intermitente. Seus solos são rasos a moderadamente profundos, sendo classificados como Neossolos Litólicos, Cambissolos Háplicos ou Luvissolos Háplicos eutróficos (BRASIL, 1973; GOMES, 2015).

A vegetação responde a tal conformação paisagística e apresenta-se como caatinga arbustiva densa ou floresta caducifólia espinhosa (CEARÁ, 1997). Em virtude da degradação ocorrente em parte dos ME, domina a caatinga arbórea-arbustiva secundária.

Presentemente, os ME úmidos são os mais ocupados e degradados, pois suas condições ambientais favorecem o desenvolvimento de diversas atividades produtivas que costumam ser executadas sem planos de manejo ou respeito à capacidade de suporte do geoambiente. Já os ME semiáridos são menos degradados e ocupados que os anteriores, porém tal quadro tende a ser revertido por conta da degradação ambiental ocorrente nos pediplanos cearenses e ausência de políticas públicas conservacionistas ou preservacionistas eficientes nestes relevos. Tal situação viabiliza a maior ocupação e degradação dos supracitados.

Diante da exploração secular dos recursos naturais desses ambientes, têm-se provocadas profundas transformações paisagísticas, que suscitam na exaustão de seus recursos naturais em favor da subsistência e crescimento econômico imediato da sociedade cearense (RODRIGUEZ; SILVA, 2002; CEARÁ, 2010; GOMES, 2015). Por isso, é imperativo o desenvolvimento de pesquisas científicas que demonstrem o potencial ambiental e econômico dos recursos dos ME secos, com o intuito de mitigar perdas naturais, econômicas e culturais, deste modo, assegurando a manutenção dos sistemas socioambientais. 
Em consonância disso, elegeu-se parte dos ME secos presentes no Centro-Oeste cearense, junto aos limites dos municípios de Tauá, Independência, Pedra Branca e Boa Viagem, como área de pesquisa deste trabalho. Isto porque se partiu da hipótese de que os referidos ME possuem elementos que fundamentam a sua conservação ou preservação como tática de assegurar a manutença da biodiversidade, a quantidade e qualidade hídrica, bem como a mitigação da degradação ambiental na área de estudo.

Desta maneira, este trabalho teve como objetivo indicar os elementos naturais que fundamentam a proposição de políticas públicas em prol da conservação ou preservação dos relevos mencionados, com a finalidade de subsidiar seu ordenamento territorial, bem como mitigar prejuízos sociais e naturais.

\section{MATERIAE E MÉTODOS}

\subsection{Os Maciços Estruturais Secos do Centro-Oeste Cearense}

A fração dos ME secos presentes no Centro-Oeste cearense elegida como objeto deste trabalho compreende um conjunto de relevos/serras contíguos. Localmente, são denominadas de serras do Cologi, do Pingo, da Borracha, do Tecelão, do Belém e das Pipocas, que se encontram inseridas nos segmentos fronteiriços dos municípios de Independência, Tauá, Boa Viagem e Pedra Branca.

Nesta perspectiva, criou-se um polígono com extensão aproximada de $80 \mathrm{~km}$, disposto de NE-SW, e com área de $879,122 \mathrm{~km}^{2}$. O referido compreende a área de estudo, isto é abrange os ME secos citados e parte do pedimento e pediplano adjacentes (Mapa 1), inseridos em razão de estas porções espaciais serem áreas de transições e possuirem olhos d'água salobros perenes. Portanto, sendo locais onde os animais silvestres vivem ou trasitam em busca de recursos naturais.

O contexto geológico regional da área pesquisada é explicado por Cavalcante et al. (2003), assim indicam que o embasamento é composto por rochas pré-cambrianas do contato litológico da Unidade Canindé do Complexo Ceará com as Unidades Tróia e Indiferenciada do Complexo Cruzeta. As rochas são representadas por paragnaisses, anfibolitos, metagabros, micaxistos, quartzitos, metacalcários, anfibolitos e granitóides (CAVALCANTE et al., 2003), que deformaram-se devido aos dinâmismos tectônicos em sistemas rúpteis e ductéis, fomentando o surgimento de estruturas de foliação, falhas, fraturas NE-SW e estruturas extencionais como diques NW-SE, controlando a cadeia de relevos examinados. 
O clima é classificado como tropical quente semiárido (CEARÁ, 1997), cujas médias térmicas e pluviométricas anuais são, respectivamente, $27^{\circ}$ Celsius $\left({ }^{\circ} \mathrm{C}\right)$ e 557,76 milímetros (mm). As chuvas temporoespacialmente irregulares são concentradas entre os meses de fevereiro e abril. A insolação anual é acima de 2.515 horas e o índice de aridez é de 0,31 (INMET, 2016; CEARÁ, 2015; 2016). Esta configuração climática permite que haja a estiagem ou a seca durante até oito meses do ano.

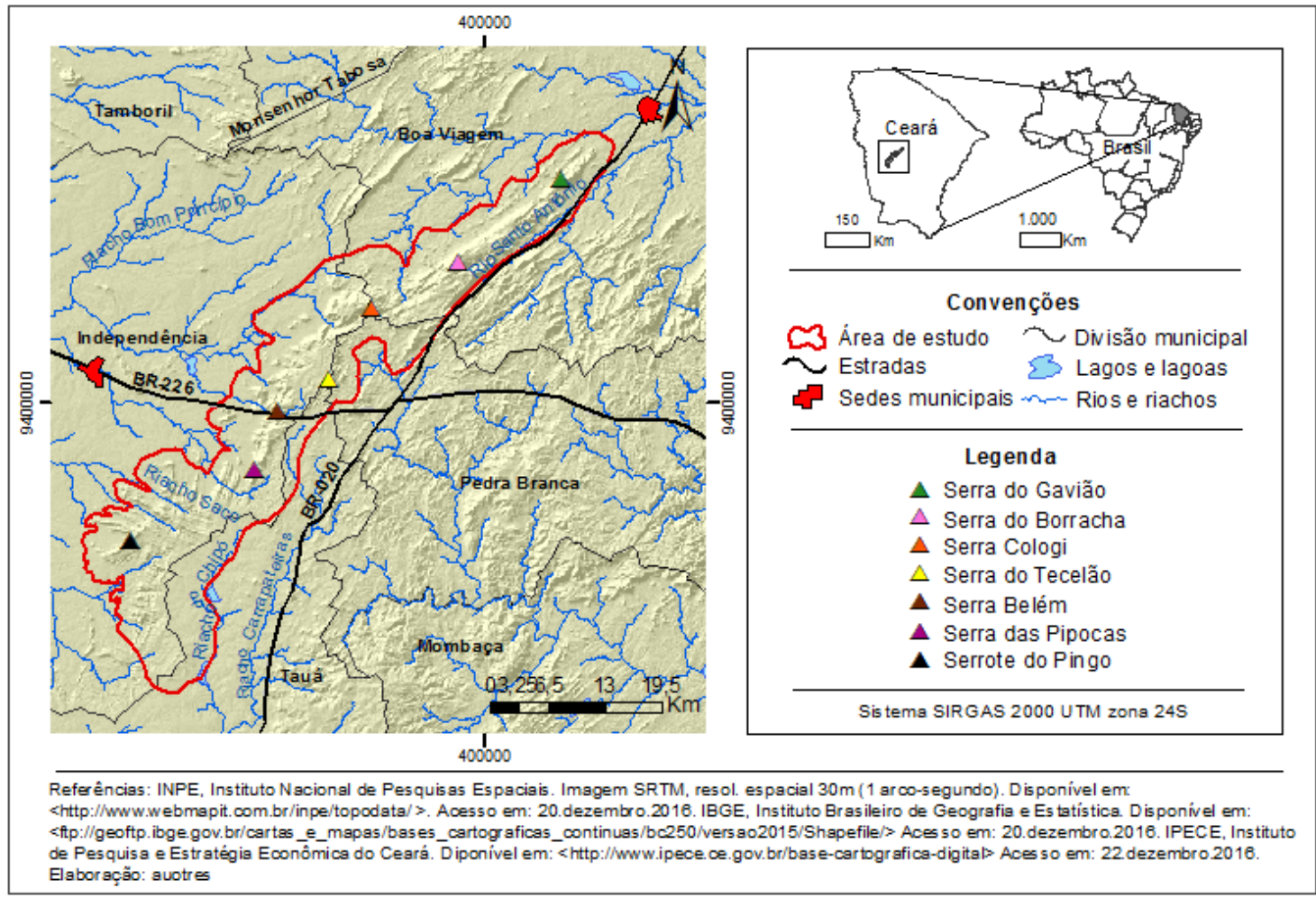

Mapa 1 - Localização dos Maciços Estruturais semiáridos do Centro-Oeste cearense objetos do estudo.

Geomorfologicamente, o polígono engloba ME dissecados e orientados de NE-SW (Mapa 2). Essa conformidade deu-se por conta da ativação de zonas de cisalhamentos e esforços tectônicos compreensivos que atuaram na direção NW-SE que fomentaram o desenvolvimento de vertentes côncavas ou convexadas voltadas para NW e SE (GOMES, 2015).

In loco, detectou-se que algumas vertentes são inclinadas superando os $45^{\circ}$, o que as tornam vulneráveis ao uso ocupação, erosão e rolamento de blocos. Ademais, os ME possuem topos convexados, planos e, nos topos aguçados em forma de cristas, podem apresentar caos 
de blocos compostos por quartzitos ou de metagranitos. Deste modo, os referidos detêm altitudes mínimas e máximas variantes entre 400 a 880m (Mapa 2 e Figura 1).

Os principais tipos de solos presentes na área são os Neossolos Litólicos Eutróficos típicos, Cambissolos Háplicos Ta Eutróficos típicos, Luvissolos Háplicos Órticos típicos, Neossolos Flúvicos Ta Eutrófico típico, Cambissolos Háplicos Ta Eutróficos lépticos e Argissolos Vermelhos-Amarelos Eutróficos típicos (BRASIL, 1973; GOMES, 2015).

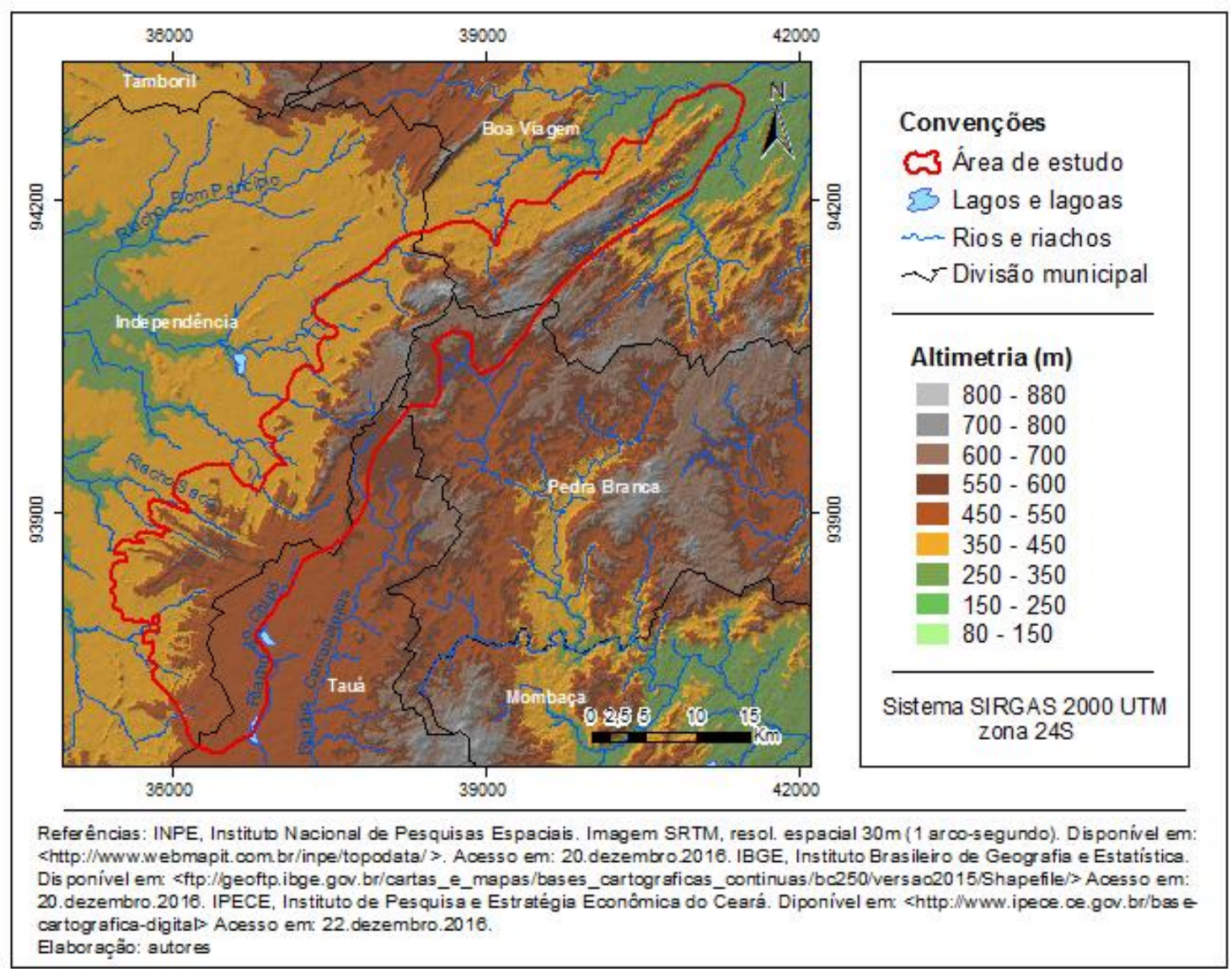

Mapa 2 - Mapa hipsométrico da área de pesquisa no Centro-Oeste cearense. 


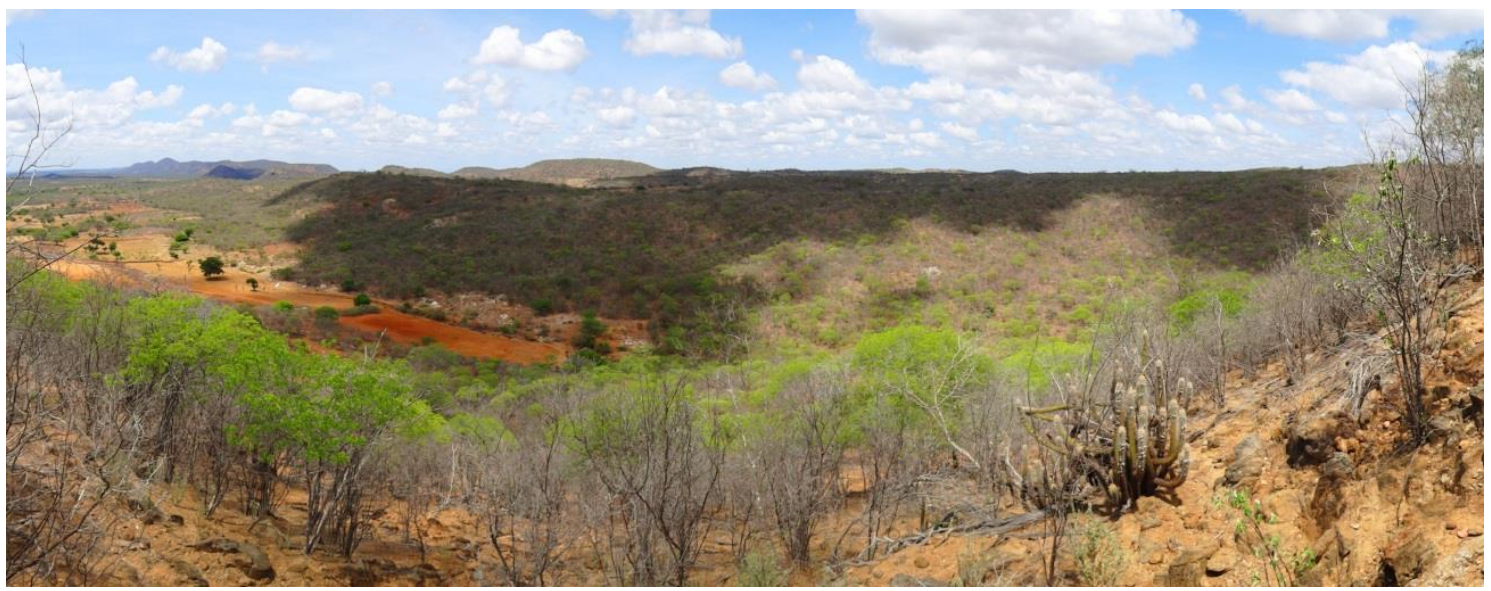

Figura 1 - Serra do Tecelão e do Belém e sua vegetação predominantemente arbustiva em Tauá - CE. Fonte: Raul C. Gomes (2015).

Diante dessa diversidade de elementos da paisagem, a vegetação varia no espaço, sobretudo onde as ações humanas foram expressivas. Classifica-se a vegetação como floresta caducifólia espinhosa ou caatinga arbórea (CEARÁ, 1997). Não obstante, em virtude do uso antrópico, essa se apresenta alterada, com fisionomia de caatinga arbórea-arbustiva aberta (Figura 1), representada por Ziziphus joazeiro Mart., Aspidosperma pyrifolium Mart., Simsia dombeyana DC., Cereus jamacaru DC, Croton blanchetianus Baill., Croton heliotropiifolius Kunth, Mimosa Caesalpiniifolia Benth., Mimosa tenuiflora (Willd.) Poir e entre outras (TRIGUEIRO; OLIVEIRA; BEZERRA, 2009; GOMES, 2015).

Tratando do uso e ocupação dos ME semiáridos, a densidade demográfica é relativamente baixa, sobretudo em razão das limitações ambientais que impõem as atividades econômicas humanas, como alta declividade, escassez hídrica, solos rasos e obstáculos para construção de estradas e barragens. Entretanto, há parte dos referidos que são ocupados por pequenos grupos familiares agropecuaristas, que detêm minifúndios ou latifúndios e são os principais responsáveis pela crescente degradação ambiental nestes relevos.

As principais atividades econômicas desenvolvidas sobre estes relevos é a agricultura de sequeiro (milho, feijão, fava, melancia, abóbora e melão caipira) e a criação de gados bovinos, caprinos e ovinos. Esses são criados extensivamente e sem práticas de manejo adequadas, o que impulsiona os desmatamentos e a degradação generalizada das paisagens. Além disso, há muitas serras que não detêm moradias em sua superfície. 


\subsection{Procedimentos Metodológicos}

A fundamentação metodológica baseou-se na abordagem sistêmica e no conceito de paisagem propostos por Bertrand (2004), que permite uma compreensão holística e funcional dos sistemas e subsistemas ambientais presentes nos ME semiáridos analisados. Este enfoque tem sido vastamente empregado nas pesquisas geográficas executadas no Nordeste brasileiro e no Ceará (RODRIGUEZ; SILVA, 2002; SOUZA, 2007; SOUZA; OLIVEIRA, 2006), suscitando na ampliação do conhecimento dos elementos, estruturas e funcionalidades das paisagens.

Com relação aos métodos procedimentais, executou-se uma série de etapas interdependentes, constituídas pela revisão da literatura existente, análises dos materiais geocartográficos sobre a área de estudo (litoestratigráfico, morfopedológico, climáticos, fitoecológico, levantamento de uso do solo) e interpretação de produtos de sensoriamento remoto e imagens de alta resolução dos contextos regional e local.

Desse modo, foi confeccionado o Modelo Digital do Terreno através de imagem SRTM (Shuttle Radar Topography Mission), com resolução espacial de 30m, que se obteve do banco de dados TOPODATA do INPE (2016). Assim, foram gerados dados de hipsometria, declividade e rede de drenagem.

Diante disso, os mapas foram produzidos em ambiente SIG (Sistema de Informações Geográficas), no sistema de coordenadas SIRGAS 2000. A categorização de 100m entre as classes topográficas foi escolhida porque esta diferença permite uma melhor visualização das cotas altimétricas do relevo examinado, evitando poluições informativas no mapa. A classificação da declividade obedeceu à referência da EMBRAPA (1997), que também atribui uma compartimentação de relevo apropriada. A rede de drenagem foi obtida a partir da classificação automática desenvolvida no SIG.

Adicionalmente, promoveram-se trabalhos de campo para o reconhecimento da verdade terrestre, delimitação de nascentes e listagem de espécies faunística e florística (com portes arbóreos e arbustivos). Neste caso, foram feitos levantamentos expeditos por meio de caminhamentos aleatórios por três seguimentos representativos da área de pesquisa, onde as espécies foram fotografadas e identificadas a partir da análise de suas características morfológicas e utilização da bibliografia especializada (RODRIGUES, 2003; MAIA, 2004; MAJOR; SALES JR.; CASTRO, 2004; REIS et al., 2006; SOUZA; LORENZI, 2008; TRIGUEIRO; OLIVEIRA; BEZERRA, 2009; GOMES, 2015). 
Para verificar a existência e a dimensão de ações erosivas sobre os solos, considerouse a presença de indícios morfológicos como sulcos, ravinas, voçorocas, microsselamento, pedestais, movimentos de massa que foram mensurados. Por isso, observou-se a superfície dos solos e alguns perfis provenientes de cortes de estradas e dos espaços degradados e/ou potenciais para preservação ou conservação.

\section{RESULTADOS E DISCUSSÕES}

No mapa de declividade (Mapa 3), é possível identificar as classes mais representativas presentes na área de estudo. Nota-se que o intervalo entre 8 a $20 \%$ é o mais expressivo sobre os ME analisados, embora haja escarpas e vertentes com aclives iguais ou superiores a $45^{\circ}$, cujo destaque na Figura 4 não é expressivo devido à escala de pequena resolução do mapa.

As Áreas de Preservação Permanente encontradas na área de estudo, conforme estabecelece Art. $4^{\circ}$ da Lei $N^{\circ} 12.651$, de 25 de maio de 2012, são olhos de d'águas com 50m de raio no entorno, encostas com declividades superiores a $45^{\circ}$ e topos ou terços superiores das elevações com mais de $100 \mathrm{~m}$ altura, com aclives médios superiores a $25^{\circ}$ (BRASIL, 2012). A partir disso, verifica-se que tais áreas são inexpressivas e pontuais no contexto posto e, por conseguinte, a legislação em vigor não assegura uma proteção eficiente para os $\mathrm{ME}$ semiáridos em voga. 


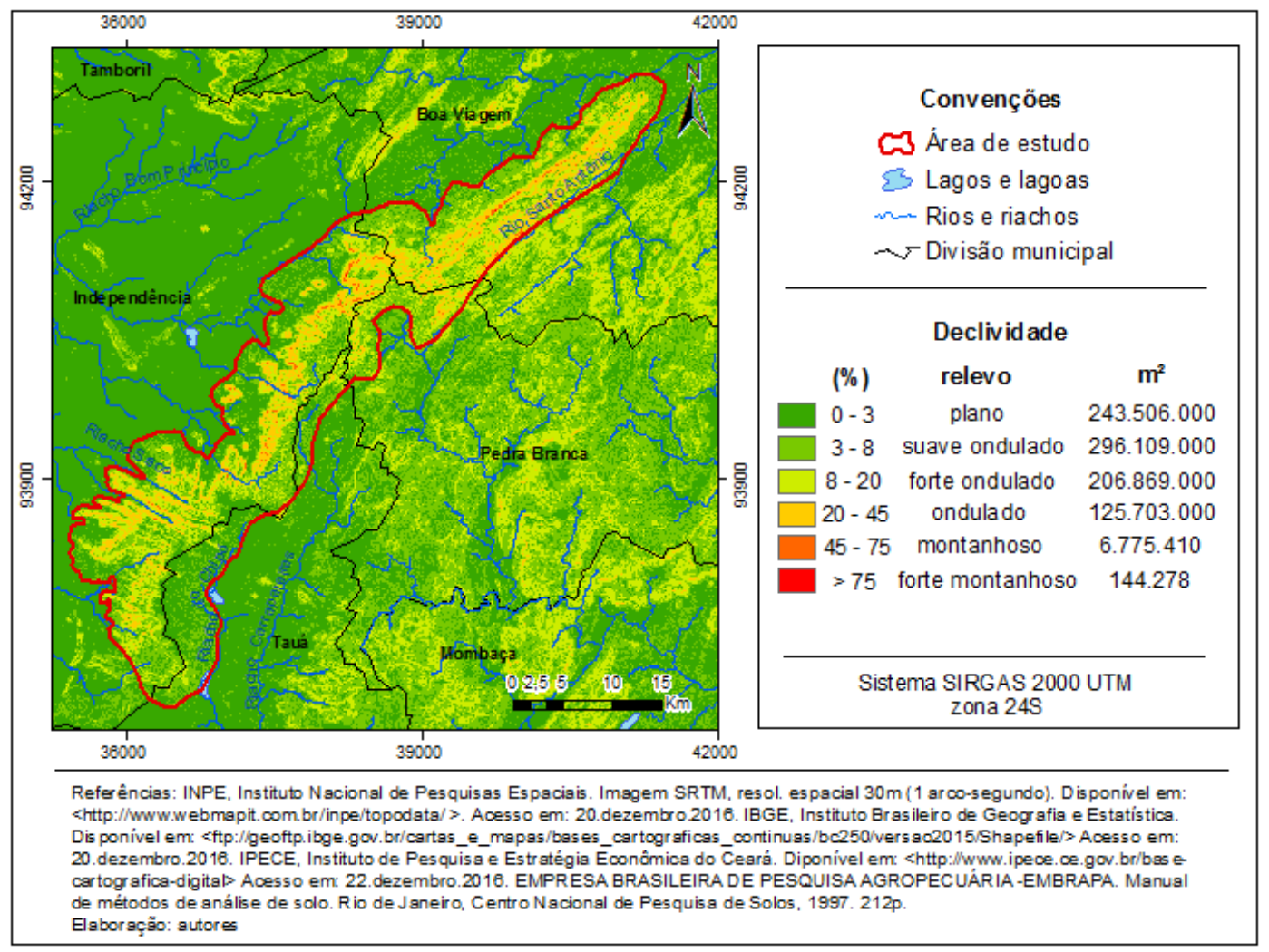

Mapa 3 - Mapa de declividade da área de pesquisa no Centro-Oeste cearense.

Em campo, observaram-se as descontinuidades que desenvolvem falhamentos nos maciços rochosos, combinadas com a angulação de algumas vertentes, propiciam condições de instabilidade das rochas. As rupturas em taludes com declividade acentuada condicionam deslizamentos, quedas de blocos rochosos de diversos tamanhos, dependendo da densidade (espaçamento) do fraturamento. Essas condições são evidenciadas principalmente no CentroNorte da poligonal, onde há relevos com maiores altitudes e com escarpas expressivas.

A suscetibilidade ao risco de movimento de massa na área é intensificada pelo desmatamento da vegetação das vertentes, provocando também a aceleração de processos de erosão concentrada nesses locais. A perda de solo por erosão desencadeia um aporte maior de sedimentos transportados em drenagens, acarretando, por conseguinte, o assoreamento de reservatorios hídricos.

No que tange ao levantamento florístico, constatou-se que os ME examinados são habitats de diversas espécies da flora da caatinga (Tabela 1), entre as quais se destaca a aroeira do sertão (Myracrodruon urundeuva), por ser uma das espécies arbóreas mais signiticativas nos topos e vertentes dos relevos e porque estava até, recentemente, ameaçada de extinção (BRASIL, 2008). Atualmente, a listagem de vegetais ameaçados apresentada por 
Brasil (2014) não a menciona. Contudo, é salutar fortalecer a proteção dos seus habitats para que não volte a figurar entre as fitoespécies ameaçadas de extinção no Brasil.

Tabela 1 - Listagem das especíeis arboreas e arbustivas encontradas na área de pesquisa.

\begin{tabular}{ccc}
\hline FAMÍLIAS/ESPÉCIES & $\begin{array}{c}\text { NOMES } \\
\text { POPULARES }\end{array}$ & HÁBITOS \\
\hline ANACARDIACEAE & Aroeira & Arbóreo \\
Myracrodruon urundeuva Allemão & & \\
APOCYNACEAE & Arbóreo \\
Aspidosperma pyrifolium Mart. & Pereiro & Arbóreo \\
BIGNONIACEAE & Ipê Amarelo & Arbóreo \\
BURSERACEAE & & \\
Commiphora leptophloeos (Mart.) J. B. Gillet & Imburana & de Espinho \\
CAPPARACEAE & & Arbustivo \\
Cynophalla flexuosa (L.) J. Presl & Feijão Bravo & \\
Combretum leprosum Mart. & Mofumbo & Arbustivo
\end{tabular}

\begin{tabular}{ccc} 
EUPHORBIACEAE & & \\
Cnidoscolus quercifolius Pohl & Faveleiro & Arbóreo \\
Croton blanchetianus Baill. & Marmeleiro & Arbustivo \\
Croton heliotropiifolius Kunth & Velame & Arbustivo \\
Euphorbia heterophylla L. & & Arbustivo \\
Jatropha mollissima (Pohl) Baill. & Peão-Bravo & Arbustivo \\
Manihot caerulescens Pohl & Maniçoba & Arbóreo \\
FABACEAE/ CAESALPINIOIDEAE & & \\
Bauhinia cheilantha (Bong.) Steud. & Mororó & Arbóreo \\
Libidibia ferrea (Mart. ex Tul.) & Jucá & Arbóreo \\
L.P.Queiroz var. ferrea & & \\
Senna spectabilis var. excelsa (Schrad.) & Canafistula & Arbóreo \\
H. S. Irwin \& Barneby & & \\
Poincianella bracteosa (Tul.) L.P. Queiroz & Catingueiro & Arbóreo \\
FABACEAE/ MIMOSOIDEAE & & \\
Albizia inundata (Mart.) Barneby \& Grimes & Muquêm & Arbóreo \\
Anadenanthera colubrina var cebil griseb altschul & Angico & Arbóreo \\
Mimosa Caesalpiniifolia Benth. & Sabiá & Arbustivo \\
Mimosa tenuiflora (Willd.) Poir & Jurema Preta & Arbustivo \\
\hline
\end{tabular}


Revista de Geografia (Recife) V. 34, No. 3, 2017

\begin{tabular}{ccc}
\hline FAMÍLIAS/ESPECIES & $\begin{array}{c}\text { NOMES } \\
\text { POPULARES }\end{array}$ & HÁBITOS \\
\hline $\begin{array}{c}\text { Piptadenia stipulacea (Benth) Ducke } \\
\text { FABACEAE/ FABOIDEAE }\end{array}$ & Jurema Branca & Arbóreo \\
Luetzelburgia auriculata (Alemão) Ducke & Pau-Mocó & Arbóreo \\
MALVACEAE & & \\
Pseudobombax marginata A. St. - Hil. & Embiratanha & Arbóreo \\
OLACACEAE & & \\
Ximenia americana L. & Ameixa & Arbóreo \\
RHAMNACEAE & & Arbóreo \\
Ziziphus joazeiro Mart & Juazeiro & \\
SAPINDACEAE & & Arbustivo \\
\hline Serjania lethalis A. St. - Hil. & Mata-Fome & A \\
\hline
\end{tabular}

Além disso, ao percorrer trilhas e veredas da área de estudo, visualizaram-se diversas espécies faunísticas (Figura 2), dentre as quais se destacam: cassaco (Didelphis albiventris), camaleão (Iguana iguana), tamanduá-mirim (Tamandua tetradactyla), o tatu (Tolypeutes tricinctus), peba (Euphractus sexcinctus), macaco prego (Cebus libidinosus) e vestígios deixados por veados catingueiros (Mazama gouazoupira), raposa (Cerdocyon thous) e onçaparda (Puma concolor). 


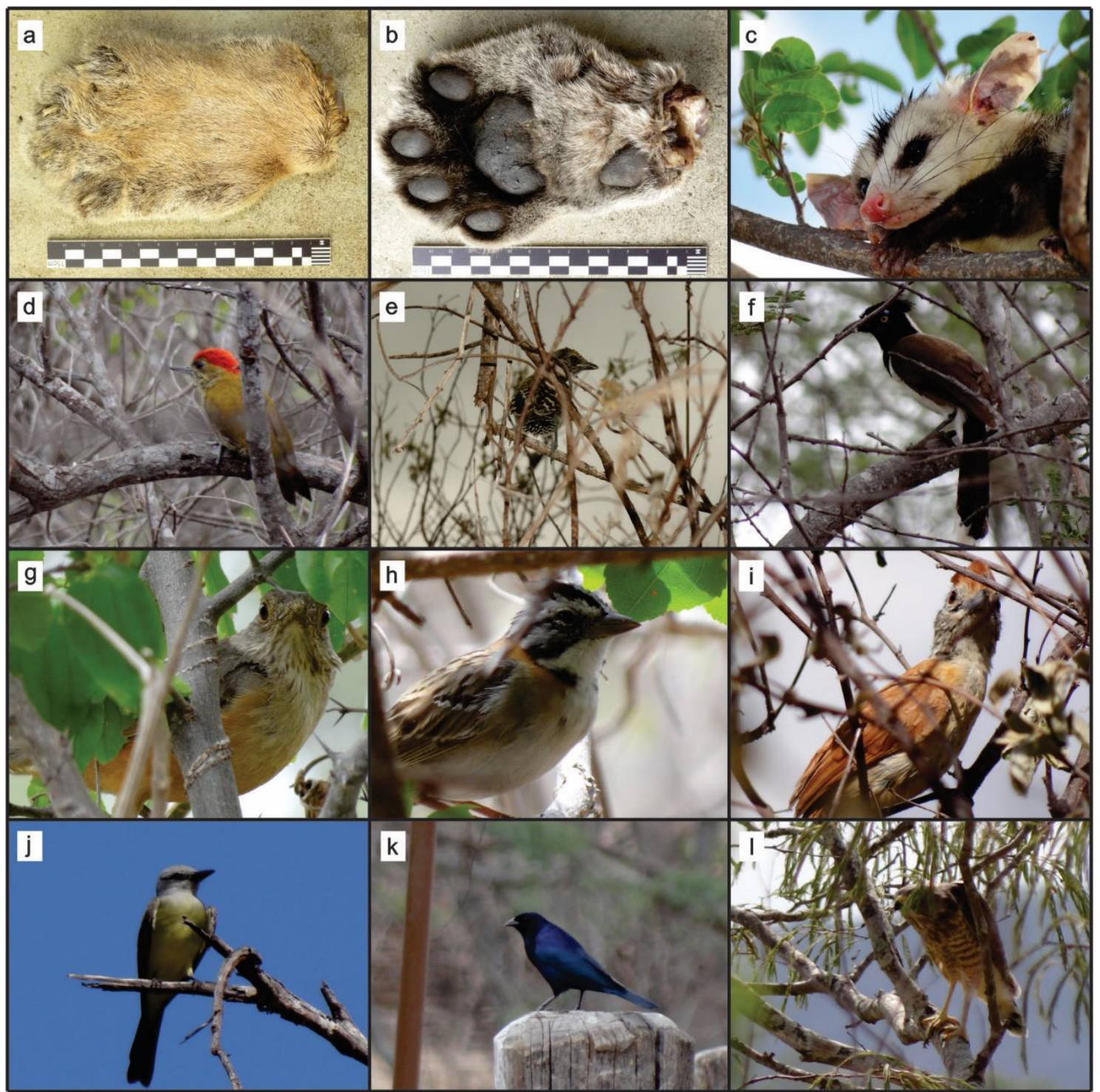

Figura 2 - Imagens de espécies faunísticas registradas na área de estudo: a e b) pata de onçaparda (Puma concolor) morta por caçadores; c) cassaco (Didelphis albiventris); d) pica-pau oliva (Veniliornis passerinus); e) choro-barrada (Thamnophilus doliatus); f) cã-cão (Cyanocorax cyanopogon); g) sabiá (Turdus rufiventris); h) tico-tico (Zonotrichia capensis); i) desconhecido; j) suiriri (Tyrannus melancholicus); k) azulão (Molothrus bonariensis) e 1) gavião-vermelho (Buteogallus meridionalis). Fonte: Raul C. Gomes (2015).

Tais animais têm sofrido com a perda de seus habitats devido à degradação ambiental ocasionada por fazendeiros e caçadores. Por não usarem práticas de manejos adequadas, empregam os solos, a água e a vegetação extensivamente, quando esses recursos não oferecem a produtividade satisfatória, migram para novos espaços, criando um circuíto de destruição e desequilíbrios ecológicos. 
Soma-se a este cenário a predação e caça dos animais silvestres, não somente para consumo, mas também para fins comerciais. Espécies como o tamanduá-mirim (Tamandua tetradactyla), o tatu (Tolypeutes tricinctus), o peba (Euphractus sexcinctus) e veados catingueiros (Mazama gouazoupira) são significativamente caçados para suplementar a alimentação dos moradores locais, sendo por vezes comercializados para angariar alguma renda em meio ao cenário de pobreza e estiagem.

Localmente, a onça-parda (Puma concolor) é um dos animais mais temidos e caçados, pois tem o histórico de dizimar dezenas de ovinos e caprinos em um curto espaço de tempo. Os ataques aos rebanhos dão-se em decorrência dos fazendeiros ocuparem os habitats originais das onças, que passam a predar os rebanhos, o que resulta na caça do felino, criando um conflito socioambiental.

O macaco-prego (Cebus libidinosus), o tatu (Tolypeutes tricinctus), o cassaco (Didelphis albiventris), o veado-catingueiro (Mazama gouazoupira), o tamanduá-mirim (Tamandua tetradactyla) e a onça-parda (Puma concolor) são os que mais sofrem com a degradação ambiental, pois carecem de um território amplo e com recursos abundantes para sobreviverem. Desta maneira, são os primeiros a perecerem como resultado da paisagem degradada. Cabe frisar que, tanto o tatu (Tolypeutes tricinctus) quanto à onça-parda (Puma concolor) estão listados como espécies ameaçadas de extinção, respectivamente, nas categorias: em perigo e vulnerável (BRASIL, 2014a).

Além do potencial biológico, detectou-se durante os trabalhos de campo, que os ME semiáridos examinados possuem várias nascentes intermitentes e algumas perenes com águas salobras. Por estarem na zona de interflúvios, as primeiras são responsáveis pelo abastecimento das bacias hidrógráficas rios Poti, Banabuiú e Jaguaribe. A relevância destas para a sociedade é atestada pela criação da Área de Relevante Interesse Ecológico (ARIE) das Águas Emendadas dos Inhamuns, Unidade de Conservação de 407,03 hectares nas serras do Tecelão e Lagoa Seca (CEARÁ, 2014).

Entretanto, a ARIE mencionada é pequena, engloba majoritariamente áreas degradadas (campos agrícolas e pastagens) e não consegue efetivamente proteger a maioria dos recursos e espaços estratégicos, como olhos d'água salobros, onde os animais silvestres obtém água. Adicionalmente, a criação da referida pouco alterou o modo de produção tradicional local, especialmente, devido à carência de investimentos, de proposição de alternativas agroecológicas, de fiscalização e de auxílio técnico estatal. Não obstante, detém 
uma função simbólica que sinaliza o interesse público em conservar as serras secas, notadamente, suas nascentes, mesmo diante das limitações apresentadas.

A progressiva degradação ambiental dos $\mathrm{ME}$ secos tem ativado a erosão laminar e em sulcos sobre os solos da área, sobretudo nos Cambissolos Háplicos, nos Neossolos Litólicos e nos Luvissolos Háplicos. Isto tem sido provocado por diversos fatores, dentre os quais despontam os desmatamentos para construção de roçados, uso das vertentes inclinadas sem práticas de terraceamento ou curvas de níveis e pelo pisoteio do gado que subsidia a ação da erosão em sulcos, doravante a formação de bad lands.

Em decorrência disso, alguns destes solos já chegaram a perder até $30 \mathrm{~cm}$ de espessura, eliminando irreversivelmente os seus horizontes A (Figura 3) e parte do Bi ou Bt. Ademais, tal fenômeno repercute parcialmente na perda da capacidade dos solos armazenarem água, comprometendo também, a quantidade e a qualidade da água na rede de drenagem e nos barramentos artificiais, os quais são assoreados e salinizados rapidamente, gerandos prejuízos sociais.

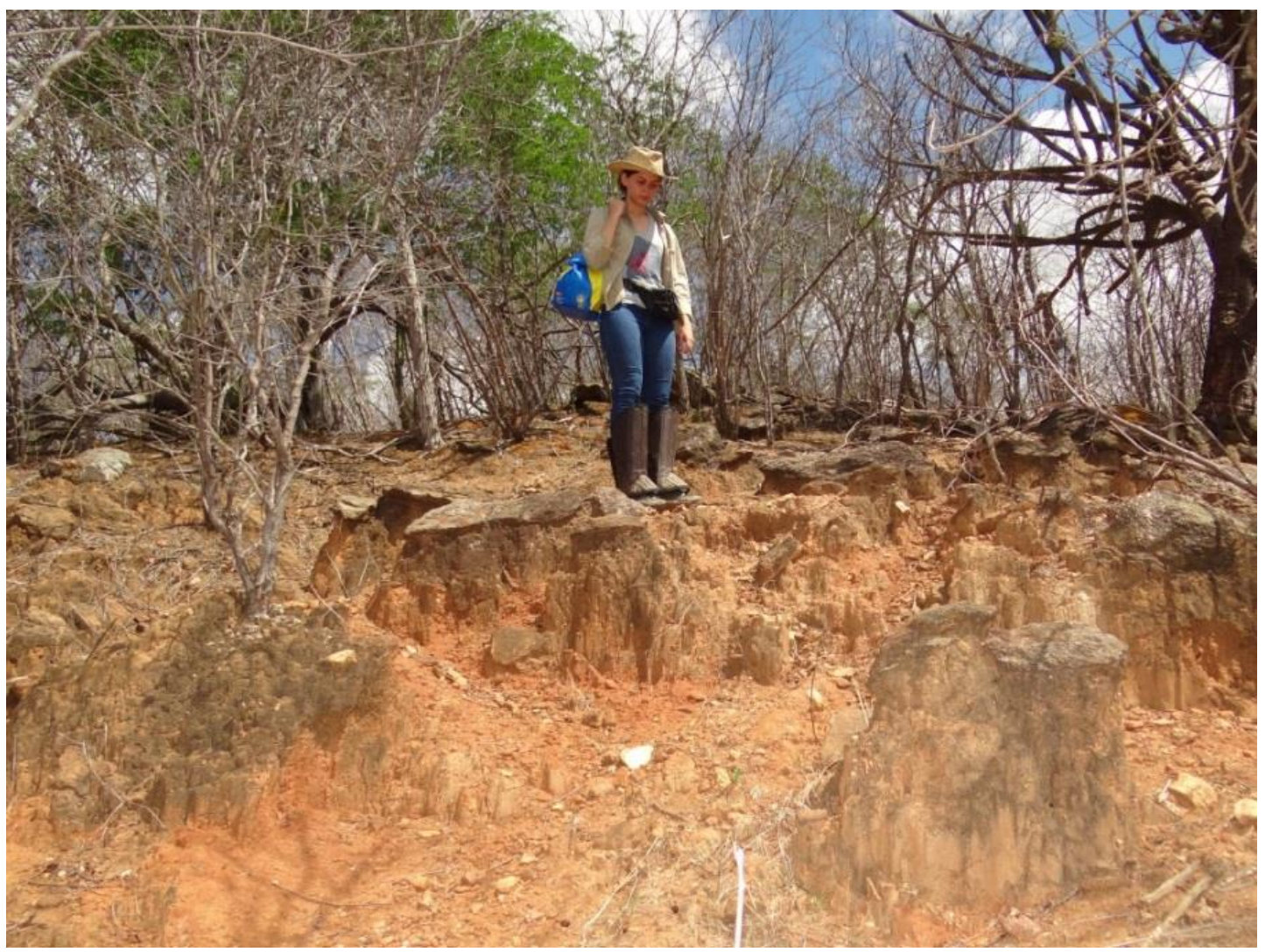

Figura 3- Pedestais/demoiselle com mais de $30 \mathrm{~cm}$ de altura em Neossolos Litólicos erodidos e presentes na área de pesquisa. Fonte: Raul C. Gomes (2015). 
Esses eventos ocorrem em diversos locais do Ceará, inclusive no açude Várzea do Boi em Tauá-CE (ARAÚJO, 2003), que barra o rio Carrapateiras, que nasce na serra do Tecelão, e recebe diversos riachos tributários oriundos da serra do Belém. Logo, os desmatamentos e a falta de proteção das matas ciliares, principalmente, junto aos olhos d'água nas serras do Tecelão, Pipoca, Belém e Conceição, por exemplo, são fatores que viabilizam a acentuação da problemática hídrica ressaltada.

A baixa densidade demográfica dos relevos é um fator positivo para propiciar a expansão da ARIE ou criação de novas unidades de conservação ou preservação. Isto porque a maioria dos ME da área estudada não possui moradias, pois estas ocupam os segmentos mais rebaixados ou planos adjacentes. Assim, são utilizados por agropecuaristas que fazem roçados e/ou criam seus animais extensivamente. Neste âmbito, o planejamento, a gestão, e uma possível desapropiciação e um novo ordenamento territorial tornam-se mais viáveis financeiramente e menos complexos.

Além disso, todos estes ME semiáridos são fortemente susceptíveis à desertificação, já que suas condições geoecológicas são frágeis e o limite entre a estabilidade dos processos morfodinâmicos e pedogenéticos é tênue e facilmente alterado pelas ações antrópicas. Neste enredo, não é casual que as atividades econômicas sem planos de manejo têm causado profundas alterações geobotânicas e prejuízos sociais nos pediplanos circundantes aos maciços tratados (OLIVEIRA, 2006; TRIGUEIRO; OLIVEIRA; BEZERRA, 2009; CEARÁ, 2010).

Desta maneira, a degradação ambiental nos pediplanos tem tornado os ME estudados em "hotspots" em meio às vastas paisagens degradadas circundantes, visto que a fauna e a flora ainda são diversificadas nos maciços examinados. Isto indica que estes espaços demandam atenção e racionalização de seu uso para evitar perdas acentuadas da biodiversidade e na alteração dos serviços ambientais por esses desenvolvidos.

\section{CONSIDERAÇÕES FINAIS}

Os ME semiáridos estudados possuem fatores ou elementos naturais que fundamentam a proposição de políticas públicas conservacionistas em prol do seu ordenamento territorial. Embora poucos setores dos maciços sejam entendidos como Àreas de Preservação Permanente, verifica-se que há diversos espaços que oferecem limitações aos usos antrópicos 
dadas às declividades, às diminutas espessuras dos solos, aos afloramentos rochosos e aos riscos de deslizamento e queda de blocos rochosos.

Averiguou-se que a proteção dos $\mathrm{ME}$ semiáridos é uma condição estratégica para evitar desequilíbrios ecológicos e assegurar a conservação de espécies vegetais e faunísticas, sobretudo aquelas consideradas vulneráveis ou ameaçadas. Com habitats conservados, as onças tenderão a diminuir os ataques aos rebanhos, diminuindo os conflitos socioambientais na região.

O ordenamento e proteção desta área impactarão positivamente sobre a manutenção dos serviços ambientais, especialmente na dimensão hídrica, pois os relevos descritos são partes dos interflúvios que comportam importantes nascentes dos rios Poti, Jaguaribe e Banabuiú. Assim, a conservação ou preservação destes espaços repercute na melhoria da quantidade e qualidade hídrica dos rios e das barragens, mitigando a possibilidade de assoreamentos e salinização dos referidos, bem como disponibilizando mais água para a sociedade cearense.

A expansão da degradação ambiental e da desertificação na área agravará o cenário de semiaridez e pobreza, comprometendo o bem-estar da população da região e expandindo os problemas socioambientais na área. Desta maneira, a proteção dos ME semiáridos estudados não se justifica exclusivamente pela conservação e/ou preservação ambiental em meio aos cenários degradados da região dos Inhamuns. Isto porque se trata de uma estratégia voltada para conservação de estoques/recursos naturais importantes para o desenvolvimento local, para as gerações futuras e para a difusão do respeito à coexistência entre os seres.

Por fim, diante do exposto, sugere-se ao Estado e as entidades conservacionaistas que direcionem suas atuações para proteção do espaço pesquisado e, se possível, iniciem a proposição de criação de uma unidade de preservação e ampliação da UC existente na área de pesquisa. Além disso, apesar da complexidade, é necessário que as unidades sejam contíguas para viabilizar sua integração e seu melhor gerenciamento, logo permitindo também que os animais desloquem-se por áreas contínuas onde poderão habitar tranquilamente, com a mínima interferência antrópica.

\section{REFERÊNCIAS}

ARAÚJO, J. C. de. Assoreamento em Reservatório do Semi-Árido: modelagem e validação. Revista Brasileiro de Recursos Hídricos, v.8, n. 2, p. 39-56, 2003. BERTRAND, G. Paisagem e Geografia Física Global: esboço metodológico. Revista RA'EGA, n.8, p. 141-152, 2004. 
BETARD, F.; PEULVAST, J. P.; CLAUDINO-SALES, V. Caracterização Morfopedológica de uma Serra Úmida no Semi-Árido do Nordeste Brasileiro: o caso do maciço de Baturité-CE. Revista Mercator, v. 6, p. 107-126, 2007.

BRASIL. SUDENE/EMBRAPA. Levantamento Exploratório de Reconhecimento de Solos do Estado do Ceará. SUDENE/ EMBRAPA, Recife - PE: Bol. Téc. No 28, Série Pedologia, 1973.

Lei $\mathbf{N}^{\circ} \mathbf{1 2 . 6 5 1}$, de 25 de maio de 2012. Dispõe sobre a proteção da vegetação nativa; altera as Leis $\mathrm{n}^{\text {os }}$ 6.938, de 31 de agosto de 1981, 9.393, de 19 de dezembro de 1996, e 11.428, de 22 de dezembro de 2006; revoga as Leis nos 4.771, de 15 de setembro de 1965, e 7.754, de 14 de abril de 1989, e a Medida Provisória no 2.166-67, de 24 de agosto de 2001; e dá outras providências. Brasília: DOU de 28/05/2012.

Ministério do Meio Ambiente. Instrução Normativa $N^{\circ} 6$, de 23 de set. de 2008.

Brasília.

Disponível

$\mathrm{em}:<$ http://www.mma.gov.br/estruturas/179/_arquivos/179_05122008033615.pdf>. Acessado em 28 de dez. 2016.

Ministério do Meio Ambiente. Portaria No 443, de 16 de dez. de 2014. Diário Oficial da República Federativa do Brasil, Poder Executivo, Brasília. Disponível em: <http://pesquisa.in.gov.br/imprensa/jsp/visualiza/index.jsp?data=18/12/2014\&jornal=1\&p agina=110\&totalArquivos=144>. Acessado em 23 de dez. 2016.

Ministério do Meio Ambiente. Portaria $N^{\circ}$ 444, de 17 de dez. de 2014a. Diário Oficial da República Federativa do Brasil, Poder Executivo, Brasília. Disponível em: $<$ http://pesquisa.in.gov.br/imprensa/jsp/visualiza/index.jsp?jornal=1\&pagina $=121 \&$ data $=1$ 8/12/2014 >. Acessado em 23 de dez. 2016.

CAVAlCANTE, J. C. et al. Mapa Geológico do Estado do Ceará- Escala 1:500.000. Fortaleza: MME/CPRM, 2003.

CEARÁ (Estado). Instituto de Planejamento do Ceará- IPLANCE. Atlas do Ceará. Fortaleza: IPLACE, 1997. 56p.

. Fundação Cearense de Meteorologia e Recursos Hídricos- FUNCEME.

Mapeamento da Cobertura Vegetal e do Uso/Ocupação do Solo da APA da Serra de Baturité- CEARÁ. Fortaleza: FUNCEME, 2006.

. Secretária dos Recursos Hídricos. Programa de Ação Estadual de Combate à

Desertificação e Mitigação dos Efeitos da Seca- PAE, CE. Fortaleza: Ministério do Meio Ambiente, 2010.

. Conselho de políticas e gestão do meio ambiente - COMPAM. Governador Cria ARIE das Águas Emendadas dos Inhamuns. Fortaleza, 03 de fev. 2014. Disponível:< http://www.conpam.ce.gov.br/index.php/sala-de-imprensa/noticias/43936-governador-criaarie-das-aguas-emendadas-dos-inhamuns>. Acessado em: 29 nov. 2016.

_. Fundação Cearense de Meteorologia e Recursos Hídricos. Índice de Aridez do Ceará. Disponível em:< http://www.funceme.br/index.php/areas/17-mapastem\%C3\%A1ticos/542-\%C3\%ADndice-de-aridez-para-o-cear\%C3\%A1>. Acessado em 23 dez. 2016.

EMBRAPA. Empresa Brasileira de Pesquisa Agropecuária. Manual de Método de Análise do Solo. Rio de Janeiro, Centro Nacional de Pesquisa de Solos, 1997. 212p

GOMES, R. C. Análise Geoambiental da Degradação do Sistema e Subsistemas da Microbacia Hidrográfica do Riacho Carrapateiras-Tauá/CE. Fortaleza: UFC, 2015. 296p. INPE, Instituto Nacional de Pesquisas Espaciais. Imagem SRTM, resol. espacial 30m (1 arco-segundo). Disponível em:<http://www.webmapit.com.br/inpe/topodata/>. Acesso em: 20 dez. 2016. 
INSTITUTO NACIONAL DE METEOROLOGIA - INMET. Dados Pluviométricos e de Temperatura de Tauá. 2016. Disponível em: <http://www.inmet.gov.br/portal/index.php?r=estacoes/estacoesAutomatica>. Acessado em: 24 nov. 2016.

MAIA, G. N. Caatinga: árvores e arbustos e suas utilidades. 1. ed. São Paulo: DeZ Computação Gráfica e Editora, 2004. 423p.

MAIA, R. P.; BEZERRA F. H. R. Condicionamento Estrutural do Relevo no Nordeste Setentrional Brasileiro. Revista Mercator, Fortaleza, v. 13, n. 1, p. 127-141, 2014.

MAJOR, I.; SALES JR., L. G.; CASTRO, R. Aves da Caatinga. Fortaleza: Edições Demócrito Rocha; Associação Caatinga, 2004. 256p.

OLIVEIRA, V. P. V. de. A Problemática da Degradação dos Recursos Naturais no Domínio dos Sertões do Estado do Ceará- Brasil. In: SILVA, J. B. da; DANTAS, E. W. C.; ZANELLA, M. E.; MEIRELES, A. J. de A. (Orgs.). Litoral e Sertão: natureza e sociedade no Nordeste brasileiro. Fortaleza: Expressões Gráficas, 2006. p.209- 222.

RODRIGUEZ, J. M. M.;SILVA, E. V. da. A Classificação das Paisagens a Partir de uma Visão Geossistêmica. Revista Mercator, Fortaleza, n.1, p.95-112, 2002.

RODRIGUES, M.T. Herpetofauna da Caatinga. In: LEAL. I. R.; TABARELLI, M.; SILVA, J. M. C. (ed.). Ecologia e Conservação da Caatinga. Recife: Editora Universitária da Federal de Pernambuco, 2003. p. 181- 236.

REIS, N. R. et al. Mamíferos do Brasil. Londrina: Nélio R. dos Reis, 2006, 437p.

SOUZA, M. J. N. de.; OLIVEIRA, V. P. V. de. Os Enclaves Úmidos e Sub-Úmidos do SemiÁrido do Nordeste Brasileiro. Revista Mercator, Fortaleza, ano 05, n.09, p.85-102, 2006.

SOUZA, M. J. N. de. Compartimentação Geoambiental do Ceará. In: SILVA, J. B. da; DANTAS, E. W. C.; CAVALCANTE, T. C. (Orgs.). Ceará: novo olhar geográfico. 2 ed. Fortaleza: Edição Demócrito Rocha, 2007. p. 127-140.

SOUZA, V. C.; LORENZI, H. Botânica Sistemática: guia ilustrado para identificação das famílias de Fanerógamas nativas e exóticas no Brasil. Nova Odessa-SP: Instituto Plantarum, 2008.

TRIGUEIRO, E. R. da Cunha; OLIVEIRA, V. P. V. de; BEZERRA, C. L. F. Indicadores biofísicos e a dinâmica da degradação/ desertificação no bioma caatinga: estudo de caso no Município de Tauá, Ceará. Revista Rede. Fortaleza, v.3, n. 1, p.62-82, 2009.

\section{AGRADECIMENTOS}

Agradecemos à Fundação Cearense de Apoio ao Desenvolvimento Científico e Tecnológico-FUNCAP e ao Conselho Nacional de Desenvolvimento Científico e TecnológicCNPQ pelas consessões de bolsas de mestrado e doutorado. 